
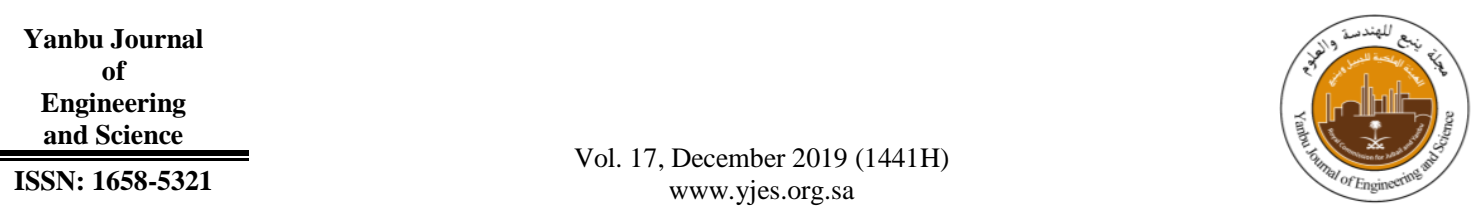

\title{
TRACING THE ROOTS OF CONSTRUCTION CONFLICTS: EXPLAINING PROBLEMS, PREFERENCES, AND PROCESS
}

\author{
Abdullah Mohammed Alshehri \\ Department of Civil and Environmental Engineering, College of Engineering, Majmaah University, Majmaah 11952, \\ Saudi Arabia \\ E-mail: a.m.alshehri@mu.edu.sa
}

\begin{abstract}
The construction industry is continuously struggling to resolve the conflicts equitably and economically. Therefore, the present study aims to trace the roots of construction conflicts by explaining problems, preferences, and processes associated with the construction industry. Quantitative research design has been employed and 116 owners, constructors, consultants, and stakeholders were recruited because of their direct involvement in the construction industry. A questionnaire was distributed among the respondents to trace the problems, preferences, and processes associated with conflicts the construction industry. The results showed that that lack of communication and coordination, contract provisions, ambiguities, bid rigging, contracting classification system, unforeseen ground conditions, and discrepancies were major reasons of conflict. The study has concluded that productivity of construction industry is significantly influenced through the implementation of realistic schedule and plan for the construction project.
\end{abstract}

Keywords: Construction Conflicts, Problems, Preferences, Process, Saudi Arabia.

\section{INTRODUCTION}

There is significant increase in complexity of construction project in nature nowadays. The organizational and contractual structures are addressed by the construction procurement by bringing the project under it. Individuals or organizations are brought together through construction projects that were initially disparate to be united and are also known as temporary project coalition or temporary multi-organization [6]. However, increased chance of interactions on project lead to conflicts in nontraditional procurement methods, where individuals are sometimes under a single organization. Studies have shown that conflicts are a great challenge within the construction industry as they may lead to litigation, project failures, and in severe cases project abandonment [10], [20], [21]. Construction industry is predisposed to disputes and conflicts due to increased pressure, toughness, and harshness associated with this industry. This makes it obvious that contractual disputes and conflicts affect the prosperity of publicly funded construction projects, negatively [6]. Construction related conflicts may also arise as a result of involvement of multidisciplinary in the projects that are inevitable, when the industry itself is facing many uncertainties [3]. The conflicts developing within the construction industry are mostly related to contractual matters such as time extension, availability of information, management and administration, quality of technical approaches, determination, and unrealistic 
customer expectations [9]. The construction stakeholders consider conflict as alarming for the construction industry and they believe that it is highly important to avoid or resolve the conflicts as soon as possible. Moreover, it has also been shown that conflicts in construction industry may impose functional and dysfunctional impact on the organization and its employees [9]. The disagreement among the internal stakeholders like contractors, subcontractors, and employees is focused in relation to the conflict management in the construction projects. The important factors that enhance project viability include; increase in the personal welfare demands and social conflicts among the external stakeholders [11]. It examined different types of infrastructure patterns, when conflict occurs [14]. On examination, the study revealed major factor that is procedure of deciding facility's location and its route. The construction industry is continuously struggling to resolve the conflicts equitably and economically. It is important to propose the conflict analysis framework for investigating the occurrence of conflict and its causes by considering the characteristics of public infrastructure projects. The understanding related to mechanisms exerting influence at the team level is limited [19]. In the similar context, the present study aims to trace the roots of construction conflicts by explaining problems, preferences, and processes associated with the construction industry. The construction industry has been chosen in this study because the undertaking of temporary projects in this sector are multicultural in nature, with their own cultural norms and values. This study would help in identifying the problems causing conflicts in the construction industry and would also help in reducing the development of conflicts in this industry.

\section{LITERATURE REVIEW}

The construction related conflicts possess instinct nature and characteristics as their sources vary from one project to another. It recruited the stakeholders and analyzed their concerns related to conflicts and its management in the infrastructure projects [12]. The results depicted a great difference in the observations of the stakeholders due to mismatch in certain expectations and perceptions related to development. This mismatch was considered to be the major reason of conflicts in the construction projects. Similarly, it used the traditional and integrated procurement method to investigate the frequency and intensity of conflicts in the construction projects [6]. The study found out certain issues that lead to conflicts in construction industry including the administrative matters and technical issues. The results also showed that traditional method possessed major weaknesses of confrontational and adversarial relationships. It conducted a study to analyze the factors causing conflicts in the construction industry by focusing on behavioural [9], technical, and contractual problems. The results demonstrated poor communication and reluctance to check for constructability as the factors if conflict due to behavioral problems. The technical problems included failure of the contractor to work competently and not receiving proper instructions from the engineer and architects on time [9]. Moreover, factors of conflict due to contractual problems include unclear contractual terms and conditions, giving late possessions, and delay in interim payment. The mechanism of conflict management is important as it imposes negative impact on the financial status of the industry. Conflicts are likely to develop when there is disagreement between two or more parties. It showed that litigious and acute conflict between contractors and project developers occur due to subsurface condition during construction [1]. Mediation and litigation along with significant impact on project schedule, profit, and relationship occur as a result of budget constraints, delay due to 
weather conditions, and error in construction documents [16]. Conflict in the form of interpersonal conflict is capable of hampering communication between the stakeholders, which diminishes the project's productivity and hinders the constructive negotiations [5]. It is important to consider the conflict management in construction industry and its impact on performance and profit generation for the sake of leadership personnel and professional management in the construction industry. The construction industry is not able to manage and provide possible solutions; although, it is well-aware about the conflicts. Therefore, it is important to extend the theory of relationship conflict into the construction management and explain its positive impact on the construction industry [5]. The internal conflicts and disputes are observed within the construction projects because of their dynamic nature affecting productivity of the industry, delayed handover, and decrease in product quality. It explained that there is significant impact of selecting right contractor on time required to complete the entire project and manage the prospects for conflict [8]. The contractor is responsible for assisting the organization of construction projects for managing the associated risks considering the increased scope of construction projects in Saudi Arabia. It demonstrated that majority of the conflicts in Saudi construction industry arise due to alteration in the designing and procurement of the project [2]. This alteration is likely to affect the productive capacity of owners, contractors, as well as the consultant team supervisors. It showed that communication within the project is significantly disrupted due to increasing conflicts that makes the project management quiet challenging [18]. Similar to this, it narrated that arousal of conflicts declines the team spirit resulting in increase in total cost of the project and also has negative impact on business association among the parties [18].

\section{MATERIAL AND METHODS}

A quantitative method has been adopted in this study to investigate the problems causing conflicts in the construction industry and would also help in reducing the development of conflicts in this industry.

\subsection{STUDY SAMPLE}

The respondents for this study have been selected through random sampling from three different sites in Saudi Arabia. A total of 116 owners, constructors, consultants, and stakeholders have been recruited in this study because of their direct involvement in the construction industry that helped in collecting validated data.

\subsection{DATA COLLECTION}

The data for this study was collected using self-administered questionnaire that was developed on the website named as survey monkey. Each question in the questionnaire has its own scale that helped in tracing the conflicts and problems arising within the construction industry. The demographic detail of all the respondents including their designation and years of experience was recorded. There was a total of five items on the questionnaire that constituted various issues and conflicts in the effective management of construction projects. The research instrument has traced problems, preferences, and processes associated with conflicts the construction industry as it results in significant increase in the specified cost and also delays the project completion. This procedure of data collected has assisted in gathering information in an effective way that would allow to take corrective measures in effective management of construction project.

\subsection{DATA ANALYSIS}

The data obtained through the questionnaire was analyzed statistically using Microsoft Excel and presented through tables and graphs. This approach used for data evaluation has helped in tracing problems, 
preferences, and processes associated with conflicts the construction industry that affect the management of construction project.

\section{RESULTS}

The responses gathered through the questionnaire were evaluated critically to trace the problems, preferences, and processes associated with conflicts in the construction industry management. Table 1 has presented the demographic details of all the respondents showing that majority of the individuals recruited from the construction industry $(35.34 \%)$ were contractors. The consultants were ranked at second position with a percentage of $28.44 \%$ followed by the owners $(20.68 \%)$ and the stakeholders $(15.51 \%)$ in Table 1 has also depicted the years of experience of the participants. On the basis of the responses received from the respondents 5-10 years, 10-20 years, and more than 20 years were same i.e. $26.72 \%$; whereas, only $19.82 \%$ of the respondents had experience of 0-5 years. The results of this study have shown the problems, preferences, and processes that are linked with the arousal of conflict in the construction industry. The respondents were asked to judge the conflicts that are likely to hamper the construction projects in Saudi Arabia. Likewise, the items included in the questionnaire have been illustrated in Table 2. The results have depicted that lack of communication and coordination, contract provisions, ambiguities, and discrepancies were major reasons of conflict.
Other reasons resulting in conflict development include client's noncompliance (3.09), bid rigging (2.91), contracting classification system (3.79), unforeseen ground conditions (2.85), soil investigation report (2.69), site selection and acquisition (2.65), utilities service at design drawing, (3.05), sitemap utilities service connection (2.92), and design faults in compliance and communication phase (3.08). The results have also shown that all the factors considered in this study had significantly affected the development of conflict in the construction industry ( $\mathrm{p}$-value $=0.000$ ).

TABLE 1: DEMOGRAPHIC DETAIL OF THE RESPONDENTS

\begin{tabular}{|c|c|c|c|}
\hline Measure & Items & Frequency & $\begin{array}{c}\text { Percentage } \\
(\%)\end{array}$ \\
\hline \multirow{4}{*}{ Designation } & $\begin{array}{l}\text { Owner/Client } \\
\text { Organization }\end{array}$ & 24 & $20.68 \%$ \\
\hline & Contractor & 41 & $35.34 \%$ \\
\hline & Consultants & 33 & $28.44 \%$ \\
\hline & Stakeholders & 18 & $15.51 \%$ \\
\hline \multirow{4}{*}{$\begin{array}{c}\text { Years of } \\
\text { Experience }\end{array}$} & $0-5$ years & 23 & $19.82 \%$ \\
\hline & $5-10$ years & 31 & $26.72 \%$ \\
\hline & $10-20$ years & 31 & $26.72 \%$ \\
\hline & $>20$ years & 31 & $26.72 \%$ \\
\hline
\end{tabular}


Yanbu Journal of Engineering and Science Vol. 17 (2019)

TABLE 2: TRACING THE FREQUENCY OF CONFLICT

\begin{tabular}{|c|c|c|c|c|c|c|}
\hline & Never & Rarely & Seldom & Often & Always & p-value \\
\hline & \multicolumn{6}{|c|}{ Frequency (\%) } \\
\hline Project Briefing & $3(3.19)$ & $12(12.7)$ & $24(36.1)$ & $26(27.6)$ & $19(20.2)$ & 0.000 \\
\hline Early Cost Estimation & $7(7.6)$ & $18(19.5)$ & $24(36.9)$ & $19(20.6)$ & $14(15.2)$ & 0.000 \\
\hline Architect Selection & $6(6.0)$ & $12(12.1)$ & $45(45.4)$ & 19(19.1) & $17(17.1)$ & 0.000 \\
\hline Contractor Selection & $4(4.3)$ & $4(4.3 \%)$ & $36(39.1)$ & $33(35.8)$ & $15(16.3)$ & 0.000 \\
\hline Tender Process & $6(6.5)$ & $12(13.0)$ & $35(38.0)$ & $27(29)$. & $12(13.0)$ & 0.000 \\
\hline Tender Cost Estimation & $3(3.3)$ & $14(15.7)$ & $36(40.4)$ & $26(29.2)$ & $10(11.2)$ & 0.000 \\
\hline Lack of Communication/ & & & & & & \\
\hline Co-ordination & $3(3.3)$ & $14(15.7)$ & $38(42.7)$ & $20(22.4)$ & $14(15.7)$ & 0.000 \\
\hline Contract Provisions & $6(6.7)$ & $17(19.1)$ & $28(31.4)$ & $23(25.8)$ & $15(16.8)$ & 0.000 \\
\hline Ambiguities/Discrepancies & $2(2.2)$ & $18(20.4)$ & $29(32)$. & $22(25.0)$ & $17(19.3)$ & 0.000 \\
\hline Client's Non-Compliance & $7(7.8)$ & $24(26.9)$ & $24(26)$. & $22(24)$. & $12(13.4)$ & 0.000 \\
\hline Bid Rigging & $6(6.5)$ & 33(35.) & $27(29)$. & $15(16.3)$ & 11(11.9) & 0.000 \\
\hline Contracting Classification System & $1(1.1)$ & $9(9.8)$ & $23(25.2)$ & $33(36.2)$ & $25(27.4)$ & 0.000 \\
\hline Unforeseen Ground Conditions & $3(3.4)$ & $25(28.7)$ & $46(52.8)$ & $8(9.2)$ & $5(5.7)$ & 0.000 \\
\hline Soil Investigation Report & $11(12.5)$ & $30(34.0)$ & $27(30)$. & $15(17.0)$ & $5(5.6)$ & 0.000 \\
\hline Site Selection \& Acquisition & $10(11.3)$ & $30(34.0)$ & $34(38.6)$ & $9(10.2)$ & $5(5.6)$ & 0.000 \\
\hline Utilities Services at Design Drawing & $6(6.5)$ & $24(26)$. & 29(31.) & $23(25)$. & $9(9.8)$ & 0.000 \\
\hline Utilities Service Connection & $8(8.7)$ & $27(29)$. & $28(30)$. & $20(21.9)$ & $8(8.7)$ & 0.000 \\
\hline Design Faults & $6(6.5)$ & 12(13.) & $49(53)$. & 17(18.) & $7(7.6)$ & 0.000 \\
\hline Contracting Performance \& & & & & & & \\
\hline & $2(2.2)$ & 13(14.) & $33(37)$ & $27(30)$ & $14(15)$ & 0.000 \\
\hline Commissioning and Completion & & & & & & \\
\hline Process & $2(2.3)$ & 11(12.) & $32(36)$ & $29(33)$ & $13(14)$ & 0.000 \\
\hline Procurement Management & $1(1.1)$ & $15(17)$ & $37(43)$ & $23(26)$ & $10(11)$ & 0.000 \\
\hline Construction Material Selection & $3(3.3)$ & 18(19) & $39(42)$ & $26(28)$ & $5(5)$ & 0.000 \\
\hline Design Change & $9(9.8)$ & 11(12.) & $24(26)$ & $(2830)$ & $19(20)$ & 0.000 \\
\hline Change in Construction Phase & $0.00 \%$ & $5(5.3)$ & $20(21)$ & $32(34)$ & $36(38)$ & 0.000 \\
\hline Payment & $3(3.1)$ & $7(7.3)$ & $19(20)$ & $34(35)$ & $32(33)$ & 0.000 \\
\hline Delay in Project Progress & 2(2) & $3(3.0)$ & 14(14.) & $36(36)$ & $43(43)$ & 0.000 \\
\hline
\end{tabular}




\section{DISCUSSION}

The results have depicted that construction industry is tasked with constructing the built environment; therefore, it is considered as a large and complex industry. The present study has presented certain factors that are associated with conflicts in the construction industry including; lack of communication and coordination, contract provisions, client's non-compliance, unforeseen ground conditions, site selection and acquisition, and design faults in communication phase. These results were consistent with the study of stating that unforeseen circumstances like any change in the construction project and extreme weather and site conditions foster rapid increase conflicts in the construction industry [22]. There is significant impact of alteration in project design after contract finalization leading to delays in project completion causing disputes and conflicts. These results were consistent with who highlighted the fact the change in design results in conflicts [13]. Moreover, demonstrated that management of construction project tend to face many problems in its planning and construction phases at the preliminary stage [15]. The study in consistent with present study recommendation stating the importance of smooth communication and involvement of economy manger to ensure effective and timely completion of the construction process. In the present study, delay in project completion is considered as second major complication that disrupts the effective management in construction industry. In the present study, the views of owners, contractors, consultants, and stakeholders have been analyzed to explain the problems, preferences, and processes associated with the construction industry. Similarly, specified the important role played by decision makers in negotiating during different stages of construction project [23]. Various parties get involved in the construction process and their preferences are either affected positively or negatively concerning the performance of construction project that ensures the project's success. The findings of present study have also depicted that conflict mostly arise in the payment system as ineffective claims and any delay in making payments lead to conflict between two parties. Moreover, endorsed that the difficulty in the payment occurs due to the inadequate administration of the project's resources, involvement of the multidisciplinary parties, and their regulation [6]. The study analysis has also shown that working capacity, contracting classification system, unforeseen ground conditions, soil investigation report, and site selection and acquisition cause problems in project management. This fact can be explained on the basis of diversified workforce of Saudi population in terms of skill set. It has been shown that work productivity of the contractors is associated with the overall productivity of the project. Moreover, the project working capacity is associated with the payment system as functioning of involved parties is significantly affected as a result of the delays in payments [17]. Furthermore, asserted that selection of contractors is monitored based on certain categories that include their financial competencies and technical capabilities [7].

\section{CONCLUSION}

The present study has traced the roots of construction conflicts by explaining the problems, preferences, and processes undergoing in the Saudi construction industry. The results have clearly depicted that there are various factors that are responsible for the development of conflicts in a construction project. The results have concluded that the successful completion of any project depends on how capable the project management team is. The productivity of construction industry is significantly influenced through the implementation of realistic schedule and plan for the construction project. The study 
results have suggested that the chances of conflicts in the Saudi Arabia construction industry can be improved by setting a realistic timeline with proper backhand working. It also signifies the importance of adequate financial resources to make made in time so to ensure adequate and timely delivery of the construction projects. However, these results are limited because it has just considered a specific population and these results cannot be applied to any other developing or developed countries due to difference in their economic conditions that includes regulatory mechanism, sociodemographic status of consumer, and technological advancements. Moreover, it was difficult to separate necessary factors effecting profit from relationship conflict because of the complexity of the construction industry. Future studies need to address the impact of relationship conflicts on profit among subcontractor management teams to generalize the findings to general contractors.

\section{REFERENCES}

[1] Ahlers, R., Brandimarte, L., Kleemans, I., \& Sadat, S.H. (2014). Ambitious development on fragile foundations: Criticalities of current large dam construction in Afghanistan. Geoforum, 54, 49-58. Doi: 10.1016/j.geoforum.2014.03.004

[2] Alshehri, A.M. (2013). Conflict in Architectural Projects: Diagnosis and Avoidance: a Study Based on Saudi Arabian Construction Industry (Doctoral dissertation, University of Manchester).

[3] Arditi, D., \& Pulket, T. (2005). Predicting the outcome of construction litigation using boosted decision trees. Journal of Computing In Civil Engineering (C) ASCE, 387-393.

[4] Braimah, N. (2013). Construction delay analysis techniques - A review of application issues and improvement needs. Buildings, 3, 506-531. Doi: 10.3390/buildings3030506

[5] Brockman, J.L. (2013) Interpersonal Conflict in construction: Cost, cause, and consequence. Journal of Construction Engineering and Management, 1-12. Doi: 10.1061/(ASCE.CO.1943-7862.0000805.
[6] Dada, M.O. (2013). Conflicts In Construction Projects Procured Under Traditional And Integrated Methods: A Correlation Analysis.

[7] Huang, X. (2011). An analysis of the selection of project contractor in the construction management process. International Journal of Business and Management, 6, 184. Doi: 10.5539/ijbm.v6n3p184

[8] Ibadov, N. (2015). Contractor selection for construction project, with the use of fuzzy preference relation. Procedia Engineering, 111, 317-323.

[9] Jaffar, N., Tharim, A.A., \& Shuib, M.N. (2011). Factors of conflict in construction industry: a literature review. Procedia Engineering, 20, 193-202. Doi: 10.1016/j.proeng.2011.11.156

[10] Kassab, M., Hegazy, T., \& Hipel, K. (2010). Computerised DSS for construction conflict resolution under uncertainty. Journal of Construction Engineering and Management, 136, 1249-1257. Doi: 10.1061/(asce)co.19437862.0000239

[11] Lee, C., Won, J. W., Jang, W., Jung, W., Han, S. H., \& Kwak, Y. H. (2017). Social conflict management framework for project viability: Case studies from Korean megaprojects. International Journal of Project Management, $35,1683-1696$

[12] Li, T.H.Y., Ng, S.T., \& Skitmore, M. (2012). Conflicts or consensus: An investigation of stakeholder concerns during the participation process of major infrastructure and construction projects in Hong Kong. Habitat International, 36, 333-342. Doi 10.1016/j.habitatint.2011.10.012

[13] Mahamid, I., Bruland, A., \& Dmaidi, N. (2011). Causes of delay in road construction projects. Journal of Management in Engineering, 28, 300-310. Doi: $10.1061 /$ (asce)me.19435479.0000096

[14] Min, J. H., Jang, W., Han, S. H., Kim, D., \& Kwak, Y. H. (2018). How conflict occurs and what causes conflict: Conflict analysis framework for public infrastructure projects. Journal of Management in Engineering, 34 04018019.

[15] Mohammed, K.A., \& Isah, A.D. (2012). Causes of delay in Nigeria construction industry. Interdisciplinary journal of contemporary research in business, 4, 785-794.

[16] Ning, Y., \& Ling, F.Y.Y. (2013) Reducing hindrances to adoption of relational behaviors in public construction projects. Journal of Construction Engineering Management, 139. Doi: 10.1061/(ASCE)CO.1943-7862.0000745 
[17] Pawar, O.A., \& Patil, R.S. (2014). Conflicts \& Disputes in Construction Projects. International Journal of Innovations in Engineering and Technology, 3(3), 48-53.

[18] Soni, S. Pandey, M. Agrawal, S. (2017). Conflicts and Disputes in Construction Projects: An Overview. Journal of Engineering Research and Application, 40-42. Doi: 10.9790/96220706074042

[19] Tabassi, A. A., Abdullah, A., \& Bryde, D. J. (2019). Conflict Management, Team Coordination, and Performance Within Multicultural Temporary Projects: Evidence From the Construction Industry. Project Management Journal, 50, 101-114.

[20] Tazelaar, F., \& Snijders, C. (2010). Dispute resolution and litigation in the construction industry. Evidence on conflicts and conflict resolution in The Netherlands and Germany. Journal of Purchasing and Supply Management, 16, 221-229. Doi: 10.1016/j.pursup.2010.08.003
[21] Tsai, J.S., \& Chi, C.S. (2009). Influences of Chinese cultural orientations and conflict management styles on construction dispute resolving strategies. Journal of Construction Engineering and management, 135, 955-964. Doi: $\quad 10.1061 /$ (asce)07339364(2009)135:10(955)

[22] Vaux, J. S. (2014). Relationship conflict in construction management and how it affects performance and profit.

[23] Yousefi, S., Hipel, K.W., \& Hegazy, T. (2010). Attitude-based negotiation methodology for the management of construction disputes. Journal of Management in Engineering, 26(3), 114-122. Doi: Yousefi, S., Hipel, K. W., \& Hegazy, T. (2010). Attitude-based negotiation methodology for the management of construction disputes. Journal of Management in Engineering, 26, 114-122. Doi: 10.1061/(asce)me.1943-5479.0000013 